\title{
MICHAEL FARADAY: O CAMINHO DA LIVRARIA À DESCOBERTA DA INDUÇÃO ELETROMAGNÉTICA
}

\author{
Michael Faraday: the road from the bookstore to the discovery \\ of electromagnetic induction
}

\author{
Valéria Silva Dias ${ }^{1}$ \\ Roberto de Andrade Martins ${ }^{2}$
}

\begin{abstract}
Resumo: Estudando o trabalho experimental sobre eletromagnetismo realizado por Michael Faraday no início do século XIX, encontramos vários elementos que poderiam ser utilizados no Ensino de Ciências. Um conhecimento histórico sobre o trabalho experimental desenvolvido por Faraday e que o levou à descoberta da indução eletromagnética pode transmitir aos estudantes uma concepção mais adequada do processo de desenvolvimento da Ciência. No entanto, isso só pode ser feito utilizando-se um estudo detalhado e bem fundamentado do processo histórico ocorrido, deixando de lado as simplificaçóes e os mitos que costumam ser apresentados.
\end{abstract}

Unitermos: Michael Faraday, desmitificação, Ensino de Ciências, História da Física, eletromagnetismo.

Abstract: The study of Michael Faraday's experimental research on electromagnetism developed in the early 19th century provides several components which could be used in Science Teaching. A historical knowledge of the experimental work that led Faraday to the discovery of electromagnetic induction may convey to students a more adequate process of the development of science. However, this can only be done by the use of a detailed and well grounded study of the historical process, leaving aside the naïve simplifications and the myths that are usually told.

Keywords: Michael Faraday, myths, Science Teaching, History of Physics, electromagnetism.

\section{História da Ciência no Ensino de Ciências}

Os últimos parâmetros curriculares nacionais evidenciaram o que diversas pesquisas relacionadas ao Ensino de Ciências apontam (Peduzzi, 2001): a fecundidade do uso da História da Ciência para que "o ensino de Física, na escola média, contribua para a formação de uma cultura científica efetiva, que permita ao indivíduo a interpretação dos fatos, fenômenos e processos naturais, situando e dimensionando a interação do ser humano com a natureza como parte da própria natureza em transformação" (Brasil, Ministério da Educação, 2002: 229).

Diante dessa perspectiva, entende-se que o Ensino de Ciências, desde o Ensino Fundamental, deve situar o aluno em uma realidade científica mais ampla na tentativa de desmitificar a visão que se tem do cientista. Não se trata apenas de se preocupar com novas metodologias, como formas de facilitar a aprendizagem dos conceitos físicos, mas levar ao aluno o conhecimento do processo de fazer Ciência, bem como a compreensão dessa Ciência como uma ferramenta útil para um diálogo com o mundo e com sua possível transformação.

Acreditando na validade do emprego da História da Ciência no ensino, o maior problema que se impõe é: como fazê-lo? Os trabalhos desenvolvidos nesse sentido, ${ }^{3}$ apontam possibilidades de discussão, na sala de aula, de influências de fatores sociais, políticos, religiosos; indicam também a importância de ilustrar aspectos da Filosofia e da metodologia da

\footnotetext{
${ }^{1}$ Doutoranda do Programa de Pós-Graduação em Educação para a Ciência, Faculdade de Ciências, Universidade Estadual Paulista, Campus de Bauru (e-mail: mfedias@uol.com.br)

2 Professor Doutor, Coordenador do Grupo de História e Teoria da Ciência, DRCC, Instituto de Física "Gleb Wataghin", Unicamp (e-mail: rmartins@ifi.unicamp.br)

${ }^{3}$ Uma abordagem geral do tema pode ser encontrada em Matthews, 1994.
} 
Ciência, como a impossibilidade de provar teorias, a mutabilidade e provisoriedade do conhecimento científico e outras questões que favoreçam a construção de uma visão orgânica e sintética sobre a Ciência. E apontam também os perigos do mau uso da História da Ciênciá: distorção e simplificação dos fatos, apresentação linear e crescente da evolução da Ciência, mitificação dos cientistas e da Ciência, que levam a uma visão ingênua e falsa do trabalho científico.

Este artigo mostrará, através da história das pesquisas de Faraday, uma possibilidade de exemplo de como a simplificação do uso da História da Ciência no Ensino de Ciências tem sido realizada, normalmente, por pessoas que não têm conhecimentos suficientes sobre o assunto, e como poderia ser feito um bom emprego da mesma. Para tanto, serão enfocados alguns fatores da história desse cientista que normalmente não aparecem nos livros texto, mas que são essenciais para o entendimento do seu trabalho e de sua trajetória científica.

É importante salientar que esse conhecimento mais profundo da história de Faraday só foi possível com um extenso trabalho de pesquisa, que incluiu a localização e estudo de sua bibliografia primária (artigos, livros, correspondência e diário de laboratório), estudo do contexto científico de sua época e do trabalho de outros cientistas, além da leitura de biografias e outras obras secundárias.

\section{A história de Faraday na sala de aula}

Embora existam bons exemplos do uso da história em livros texto ${ }^{5}$, isso ainda não se constitui a regra e sim exceção. Na grande maioria das vezes em que elementos da história de uma determinada Ciência são levados à sala de aula incluídos nos livros didáticos do Ensino Médio (alguns livros não fazem referência à História da Ciência que abordam), isso se dá por meio da apresentação do "surgimento" (normalmente descontextualizado) de uma grande teoria que "derruba" a teoria anteriormente vigente; de alguns aspectos da biografia de cientistas, descritos de forma caricatural, ou somente com fotos dos mesmos. ${ }^{6}$

É no estudo de eletromagnetismo que o nome de Michael Faraday surge como um personagem importante. Freqüentemente repete-se nestes momentos que Faraday era um garoto pobre, que muito pequeno já trabalhava como ajudante de um livreiro e que foi lendo os livros da livraria e percebeu que tinha algo especial, algo como uma genialidade escondida, cujo despertar permitiu torná-lo, posteriormente, um grande cientista. Em uma mesma frase, Faraday passa de ajudante em uma livraria ao "descobrimento" da lei da indução. Mas, o que existe entre esses dois momentos?

Além disso, o que foi que Faraday descobriu? Seu trabalho foi essencialmente experimental (o que não significa que ele não tivesse pressupostos teóricos emergentes da produção científica na área) e qualitativo (sem medidas), e ele não chegou a nenhuma lei quantitativa da indução. Costuma-se apresentar, didaticamente, a indução eletromagnética falando sobre a corrente elétrica que é induzida em uma bobina quando se move um ímã em sua proximidade, mas não foi esse tipo de fenômeno que Faraday estudou, inicialmente.

A trajetória percorrida por Faraday até chegar à elaboração de lei da indução mostra que seus progressos dependeram muito mais de trabalho de pesquisa, de leitura e estudo, de seu interesse e esforços, do que de uma superioridade intelectual incomum. A próxima seção relata uma parte dessa trajetória visando esclarecer essas convicçóes.

\footnotetext{
${ }^{4}$ Para uma discussão desse tema veja Martins \& Silva, 2001.

${ }^{5}$ Um exemplo pode ser visto em Bonjorno (et al.), 2003.

${ }^{6}$ Como exemplos podem ser consultados os livros de larga utilização no Ensino Médio: Máximo e Alvarenga, 2000; Paraná, 1999; GREF, 1998.

${ }^{7}$ Mesmo em projetos inovadores como a coleção elaborada por Silva, Pinto e Leite (2000) podemos ver, no fascículo dedicado às leis do eletromagnetismo, um exemplo desse tipo de colocação.
} 


\section{A história de Faraday segundo uma pesquisa histórica}

Para estudar o trabalho de Faraday sobre eletromagnetismo, foram utilizados os trabalhos publicados pelo próprio Faraday, no período; além disso, foi consultado seu diário de laboratório ${ }^{8}$ que contém anotações de setembro de 1820 até março de 1862 . Foi utilizado apenas o primeiro de sete volumes, compreendendo o período de setembro de 1820 a junho de 1832. Também foi empregado somente o primeiro volume da correspondência de Faraday ${ }^{9}$, editado por Frank A. J. L. James, abrangendo o que foi mantido do período de 1811 a 1831. A correspondência que foi conservada do período aqui estudado é bastante incompleta; aparentemente Faraday não guardava rascunhos ou cópias das correspondências que escrevia e enviava, assim muitas se perderam. Foi conservada maior quantidade de correspondência passiva (recebida) do que ativa (escrita pelo próprio Faraday).

Com este material foi possível tentar acompanhar e compreender quais as idéias que guiaram as pesquisas de Faraday sobre eletromagnetismo, que resultaram na publicação de seis artigos em revistas e jornais conceituados no meio científico da época e no crescimento de sua reputação neste meio.

A história aqui apresentada será dividida em quatro partes. A primeira fará um breve retrato biográfico, apresentando a trajetória de Faraday através das datas mais relevantes de sua história. Depois o artigo focalizará o ano de 1820 e os desdobramentos da descoberta do eletromagnetismo. As pesquisas de Faraday nesta área podem ser divididas em três períodos: 1820 a 1821, retratando as pesquisas iniciais, prioritariamente baseadas na reprodução de experimentos publicados por outros pesquisadores; 1821 a 1823, enfocando o começo de uma atividade inovadora, que passou a contribuir com o desenvolvimento da área; 1825 a 1832, onde será mostrada a trajetória de investigações e questionamentos das teorias da época até a experiência da indução eletromagnética.

\section{Um breve relato biográfico}

Michael Faraday nasceu em 22 de setembro de 1791, em Newington Butts, Surrey. ${ }^{10}$ Seus pais, James Faraday (que trabalhava como ferreiro) e Margaret Hastwell, já tinham dois filhos: Elizabeth e Robert. A família se mudou para Londres quando Faraday tinha cinco anos, época em que a Inglaterra sofria as conseqüências da Revolução Francesa. A situação financeira da família era ruim e Michael teve uma precária formação básica, aprendendo somente o necessário para ler, escrever e um pouco de Matemática.

Em 1804, com 13 anos, Faraday começou a trabalhar para G. Riebau, como ajudante em sua livraria. Sua função era transportar o material e ajudar nas encadernações. Nesse contato com os livros ele teve a oportunidade de melhorar sua formação, lendo com grande interesse todos os livros que podia.

Em 1812, através da ajuda de um cliente da livraria, assistiu a uma série de quatro conferências do químico Humphry Davy, na Royal Institution. Anotou cuidadosamente essas conferências e enviou uma cópia para Davy, pedindo-lhe um emprego em qualquer função relacionada à Ciência. Em março do ano seguinte, com a demissão de um assistente, Faraday

\footnotetext{
${ }^{8}$ Faraday's Diary. Being the various philosophical notes of experimental investigation made by Michael Faraday (Martin, 1932-1936).

${ }^{9}$ The correspondence of Michael Faraday (James, 1991).

${ }^{10}$ As informaçōes biográficas são baseadas principalmente em Tyndall (1961) e Williams (1971). 
conseguiu o emprego. Então, aos 22 anos, Faraday tornou-se auxiliar de laboratório de Humphry Davy na Royal Institution de Londres.

Em outubro de 1813, Faraday acompanhou Davy em uma viagem pela França, Itália e Suíça, onde manteve contato com cientistas de diferentes áreas e aprendeu a "ver" e "pensar" os problemas científicos. Durante vários anos, apenas auxiliou Davy em seus estudos em Química e foi assim que adquiriu um enorme traquejo experimental. Davy foi um químico brilhante e seu laboratório era um dos mais bem equipados da Inglaterra. Com ele, Faraday fez um estudo sobre o cloro, experiências sobre difusão de gases e liqüefação, dentre tantas outras atividades sobre Química.

Até 1820 Faraday não havia se dedicado a pesquisas físicas. Neste ano, Hans Christian Ørsted divulgou a descoberta do eletromagnetismo (Martins, 1986), e o novo fenômeno despertou o interesse de muitos investigadores - incluindo Humphry Davy. Motivado por esses estudos, aos 29 anos Faraday iniciou uma série de trabalhos independentes sobre eletromagnetismo, sempre intercalados pelos estudos sobre Química.

Em 1821, Faraday fez suas primeiras conferências e começou a publicar seus trabalhos independentes. Casou-se com Sarah Barnad neste mesmo ano, e foi recomendado por Davy para sucedê-lo na superintendência do laboratório. A partir desse período, o trabalho de Faraday já era independente. Em 1824 ele se tornou membro da Royal Society, por seus trabalhos sobre Química. Em 1825 ele se tornou diretor do laboratório, e no ano seguinte iniciou uma série de conferências semanais, às sextas-feiras. Até 1830 os trabalhos principais de Faraday foram sobre Química. Em 1831, com a descoberta da indução eletromagnética, Faraday iniciou um período em que se envolveu cada vez mais com pesquisas físicas, sem nunca abandonar, no entanto, a Química.

Durante sua vida, foi chamado para consultoria em diversos trabalhos públicos e por 30 anos foi conselheiro da Trinity House. Sem nunca ter cursado uma universidade, recebeu títulos honorários e homenagens de toda parte do mundo, e ambos, Royal Society e Royal Institution, tentaram persuadi-lo a aceitar a presidência, sem sucesso.

No verão de 1858, Faraday se aposentou, após 38 anos de trabalho na Royal Institution. Morreu em 25 de agosto de 1867, em Hampton Court Green, Londres.

\section{Primeira fase de pesquisas: $1820-1821$}

A descoberta de Ørsted, publicada em artigo datado de 21 de junho de 1820 (Ørsted, 1986), desencadeou um grande interesse na comunidade científica da época e também Davy começou a investigar o assunto. Ele realizou uma série de experimentos e Faraday foi seu assistente, tendo desta forma seu primeiro contato com o eletromagnetismo.

Em setembro daquele ano, Faraday descreveu uma série de experimentos realizados em sete dias, sobre rotações eletromagnéticas, mas sua correspondência traz evidências de que outros experimentos foram anteriormente realizados. Em 11 de agosto de 1821, Faraday recebeu uma carta ${ }^{11}$ de Richard Phillips, onde o autor indagava a Faraday sobre suas pesquisas em eletromagnetismo e sobre um artigo que teria sido encomendado por ele a Faraday.

Numa outra carta ${ }^{12}$, também de R. Phillips para Faraday, esta datada de 4 de setembro, Phillips acusou o recebimento do artigo, citado anteriormente, e assegurou que sua publicação seria feita anonimamente, como pedido por Faraday:

\footnotetext{
${ }^{11}$ The correspondence of Michael Faraday. Carta 145 (James, 1991, vol. 1, p. 219).

${ }^{12}$ The correspondence of Michael Faraday. Carta 147, vol. 1, p. 220. 


\begin{abstract}
Eu li hoje o artigo sobre eletromagnetismo, e nem necessito dizer que este tem minha inteira aprovação, sendo exatamente o que eu queria. [...] Eu tomarei todos os cuidados para manter seu nome privado, mas não tenho a minima objeção de tornar este conhecido quando você desejar tout au contraire - quanto mais cedo, melhor (Phillips, in James, 1991, p. 220).
\end{abstract}

Esses dados revelam que, embora não esteja claro em quais circunstâncias, Faraday foi convidado a escrever um artigo de revisão sobre o eletromagnetismo, para a revista Annals of Philosophy. Sabemos que ele aceitou o convite e preferiu que seu nome não aparecesse na publicação $^{I 3}$; a carta citada não traz qualquer indicação a respeito do motivo, e as cartas de Faraday para Phillips se perderam.

Sabemos também que Faraday se dedicou a ler um grande número dos trabalhos que haviam sido publicados até então e redigiu um artigo que foi publicado em três partes, sob o título de "Historical sketch of electro-magnetism" (Faraday, 1821a, 1822b).

$\mathrm{Na}$ primeira parte do artigo Faraday fez um resumo do trabalho realizado por Ørsted, suas considerações e hipóteses que levaram à descoberta do eletromagnetismo. $\mathrm{Na}$ segunda parte, ele descreveu a contribuição dos pesquisadores posteriores a Ørsted, centralizando-se apenas nos fenômenos descobertos e evitando fazer consideraçôes sobre os fatos. Ele analisou principalmente o trabalho de pesquisadores franceses, mencionando Arago, que foi o primeiro físico francês a tomar conhecimento da descoberta de Ørsted e a comunicá-la à Academia de Ciências de Paris, permitindo desta forma que Ampère tomasse conhecimento desse trabalho.

Ampère logo se tornou um dos pesquisadores mais ativos na área, repetindo, variando e aplicando os resultados dos experimentos de Ørsted. Em seu trabalho propôs a redução dos fenômenos magnéticos a efeitos puramente elétricos e descobriu e analisou a interação entre duas correntes elétricas ${ }^{14}$. Faraday comentou os resultados alcançados por Ampère:

\title{
Duas correntes elétricas se atraem quando se movem paralelas entre si e na mesma direção, e se
} repelem quando elas se movem paralelas entre si em direçôes contrárias. (Faraday, 1821a, p. 276).

Nesses dois primeiros artigos sobre eletromagnetismo, Faraday não apresentou nenhuma contribuição original. Mas, estimulado pela leitura dos artigos que precisou consultar e intrigado, talvez, por alguns resultados estranhos encontrados na repetição dos experimentos (Faraday, 1823), começou a fazer novas investigações na Royal Institution que o conduziram a novas descobertas.

\section{Segunda fase de pesquisas: 1821-1823}

As primeiras experiências foram guiadas pela idéia (que, atualmente, sabemos estar errada) de que um fio conduzindo corrente deveria atrair ou repelir os pólos magnéticos de uma agulha magnética. Faraday colocou o fio condutor em uma posição vertical. Aproximando uma agulha para verificar as posições de atração e repulsão, Faraday encontrou que para cada pólo existiam duas posições atrativas e duas repulsivas (Figura 1), permitindo que a agulha tomasse sua posição original em relação ao fio.

\footnotetext{
${ }^{13}$ Somente em 1823, com "Historical statement respecting electro-magnetic rotation", publicada no Quarterly Journal of Science (Faraday, 1823) é que ele assumiu a autoria destes artigos, para provar seu conhecimento na área, pois estava sendo acusado de ter-se apropriado das idéias de outro cientista.

${ }^{14}$ Utilizando as palavras de Martins, 1986: "Ampère sugere que o magnetismo é um fenômeno secundário, e que na superfície dos imãs existiam correntes elétricas fechadas, invisiveis, responsáveis por seus efeitos."
} 

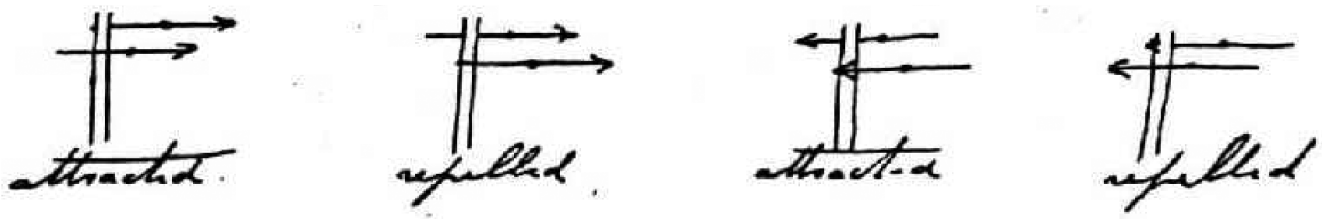

Figura 1: Posições encontradas para cada pólo da agulha magnetizada: 2 de atração e 2 de repulsão.

Esse resultado não era o mesmo encontrado por Ørsted, para quem não existia uma posição atrativa e uma repulsiva para cada pólo. $\mathrm{Na}$ descrição dos resultados apresentados no artigo, Faraday escreveu:

Aproximando o fio, perpendicularmente, na direção de um pólo de uma agulha, este se desviará para um lado, segundo a atração ou repulsão dada na extremidade do pólo; mas, se o fio é continuamente aproximado do centro do movimento [o meio da agulha magnética], por um lado ou pelo outro da agulha, a tendência da agulha de mover-se na direção anterior diminui até anular-se, de forma que a agulha torna-se indiferente ao fio. Finalmente, o movimento se inverte e a agulha é fortemente forçada a passar pelo caminho oposto (Faraday, 1821b, p. 74).

A partir de experimentos como este, Faraday se convenceu, primeiramente, de que os pólos da agulha magnética não estavam exatamente nas suas pontas, mas a uma certa distância das extremidades, no eixo da agulha. Porém, o resultado mais importante dos experimentos foi que, repetindo-os e observando os movimentos, Faraday se convenceu de que, ao invés de sofrer atração e repulsão, o pólo magnético da agulha tendia a girar em torno do fio condutor.

Esses resultados eram compatíveis com a interpretação de Ørsted que, ao invés de descrever atrações e repulsões, descrevia os movimentos de rotação da agulha magnética, ou seja, estava preocupado com questôes de direcionamento e não de forças. Faraday elaborou, então, vários experimentos para verificar tais conclusões.

Faraday conseguiu, inicialmente, produzir a rotação de um fio condutor em torno de um ímã e, posteriormente, conseguiu fazer o pólo girar ao redor do fio (Figura 2). Nos dois experimentos ao inverter a corrente elétrica, observou que a rotação mudava de sentido.

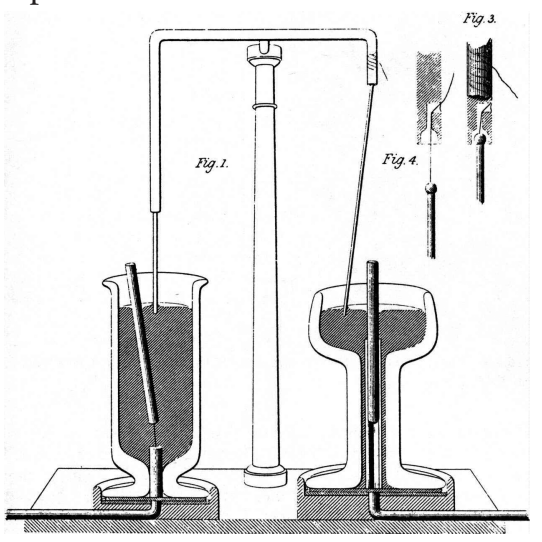

Figura 2: Esse aparelho permite observar tanto a rotação de um fio em torno de um ímã (lado direito) como a rotação de um ímã em torno de um fio condutor (lado esquerdo) ${ }^{15}$.

${ }^{15}$ Uma descrição detalhada do aparelho pode ser encontrada em Faraday, 1821d. 
As rotações eletromagnéticas se constituíram numa contribuição importante ao desenvolvimento da nova área e o artigo de Faraday (1821b), bastante longo e repleto de experimentos e discussões, foi rapidamente traduzido para o francês (Faraday, 19821c) e acrescido de comentários escritos por Ampère.

Estes experimentos levaram a uma intensa correspondência entre os dois e logo no início do ano seguinte, em carta $^{16}$ datada de 23 de janeiro de 1822, Ampère escreveu para Faraday descrevendo a repetição e analisando os experimentos de rotação eletromagnética, sugerindo que tais experimentos poderiam ser utilizados como provas da existência das correntes elétricas no interior dos ímãs. Em resposta, Faraday escreveu uma carta ${ }^{17}$ para Ampère em 2 de fevereiro, onde disse:

A rotação do imã me parece ocorrer em conseqüência das diferentes partículas, das quais este é composto, serem colocadas, pela passagem da corrente, no mesmo estado que o fio de comunicação entre os pólos voltaicos assume em relação à posição do pólo magnético (Faraday in James, 1991, p. 251).

Em seguida, Faraday explicou o que queria dizer: o motivo básico da rotação do ímã em torno de seu eixo não seria a existência de correntes circulares em seu interior, mas sim uma interação entre a corrente elétrica que passa por ele e os pólos magnéticos do próprio ímã.

A descoberta dos novos fenômenos de rotação havia desviado Faraday de seu trabalho de revisão bibliográfica para os Annals of Philosophy. No entanto, pouco depois ele completou a terceira parte desse trabalho. Neste artigo, ainda publicado anonimamente, Faraday inicialmente fez um relato das teorias existentes sobre eletromagnetismo, que ele considerava serem as mais significativas. Neste, cita: Ørsted, Berzelius, Wollaston, Schweigger, Ridolfi e Ampère, apontando que as idéias deste último seriam as mais completas e precisas, embora necessitando ser desenvolvidas em maior profundidade.

A última publicação de Faraday desta seqüência se deu em 1823, no Quarterly Journal of Science, com o título: "Historical statement respecting electro-magnetic rotation" (Faraday, 1823). O artigo apresentou sua argumentação contra acusações de ter-se apropriado indevidamente das idéias de Wollaston na questão da rotação eletromagnética. Como Wollaston era um importante personagem da época, além de ser amigo de Davy, é provável que Faraday estivesse em grandes apuros por causa dessa acusação.

Mesmo após essas acusaçôes, em 18 de janeiro de 1823, Faraday voltou a trabalhar nos experimentos eletromagnéticos, começando uma seqüência de vinte e quatro experimentos sobre rotaçôes, com um enfoque bastante diferente do que tinha feito anteriormente. Todos eles estão relacionados a fenômenos de rotação de fios ou ímãs em torno de seus próprios eixos - um problema importante sob o ponto de vista da discussão entre Faraday e Ampère.

\section{Terceira fase de pesquisas: $1825-1832$}

Depois de uma pausa, Faraday voltou a publicar sobre o assunto em 1825, no Quarterly Journal of Science, um trabalho bem curto (Faraday, 1825), onde apresentou resultados negativos de sua primeira tentativa de influenciar a intensidade de correntes elétricas através de um ímã.

\footnotetext{
${ }^{16}$ The correspondence of Michael Faraday, carta 162 (James, 1991, vol. 1, p. 245).

${ }^{17}$ The correspondence of Michael Faraday, carta 165 (James, 1991, vol. 1, p. 251-252).
} 
Como a corrente elétrica [...] afeta poderosamente um imã, tendendo a fazer seus pólos passarem ao redor do fio [...] a esperança era, por várias razôes, que a aproximação de um pólo de um poderoso imã diminuiria a corrente de eletricidade [...] (Faraday, 1825, p. 338).

O experimento consistiu em conectar os pólos de uma bateria por um fio metálico, em forma de solenóide, com a extremidade ligada a um galvanômetro. Dentro do solenóide foi inserido um ímã e procurou-se observar alguma deflexão na agulha do galvanômetro. Sabemos que deveria ter ocorrido algum efeito nesses experimentos (durante os instantes em que Faraday movia os ímãs), mas esses efeitos não foram observados.

Uma $\operatorname{carta}^{18}$ enviada a Faraday por Peter Barlow mostra que Faraday também esteve interessado, nesta época, nos experimentos apresentados por Arago na Academia de Ciências de Paris.

O fenômeno com o qual ele entreteve a Academia hoje é, por assim dizer, o inverso do anterior. Já que uma agulha em movimento é freada por uma placa em repouso, o Sr. Arago pensou que deveria seguir-se que uma agulha em repouso seria arrastada por uma placa em movimento (Arago, 1825, p. 325).

Antes porém, da realização de experimentos semelhantes aos de Arago (intitulados em seu diário por "Experimentos de indução elétrica em imitação aos experimentos de Arago na rotação de ímãs"), Faraday realizou outros em 28 de novembro de 1825: "Experimentos de indução pela conexão de fio na bateria voltaica". Aparentemente ele utilizou aqui a palavra "indução" em analogia ao que se observa no caso da eletricidade estática, em que a presença de uma carga elétrica induz uma carga oposta em corpos próximos.

Durante os anos seguintes, ele afastou-se quase totalmente das pesquisas eletromagnéticas, como mostra a ausência completa desse assunto em seu diário de laboratório e em suas publicações. Porém, um registro no diário, realizado em 22 de abril de 1828, mostra que Faraday não tinha abandonado sua busca. Nessa anotação ele descreveu um experimento em que fez um anel com fio de cobre (soldando suas extremidades) e fixou-o com um pedaço de fio para sustentá-lo com numa balança de torção (Figura 3). Introduziu no anel o pólo de um ímã em barra, depois aproximou outros ímãs em diferentes posiçôes e não observou nenhum efeito. Aproximou um ímã em forma de ferradura do fio, conectando seus pólos, mas esse circuito fechado também não apresentou efeito observável. Repetiu o experimento torcendo as extremidades do fio para formar o anel (no lugar da solda) e usando platina e prata no lugar de cobre. Não obteve resultados.

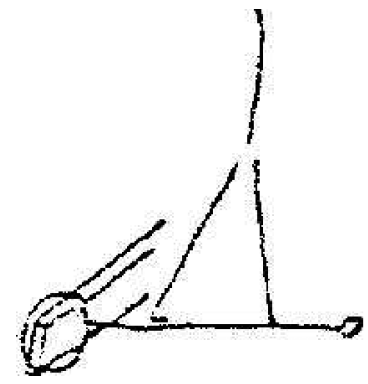

Figura 3: Anel de cobre suspenso: procurando produção de corrente pelo magnetismo.

${ }^{18}$ The correspondence of Michael Faraday, carta 253 (James, 1991, vol. 1, p. 368). 
Foi um experimento isolado em meio a suas experiências de Química e o resultado negativo parece não tê-lo motivado a prosseguir naquele momento. Uma nova fase de pesquisas sobre eletromagnetismo se iniciou somente em 1831, quando Faraday encontrou o que parece ter buscado desde o final de 1825: a indução eletromagnética.

Essas consideraçôes, com suas conseqüências, a esperança de obter eletricidade do magnetismo comum, estimulou-me várias vezes a investigar experimentalmente o efeito indutivo das correntes elétricas. Eu, ultimamente, cheguei a resultados positivos, e não apenas tive minhas expectativas realizadas, mas obtive a chave que parece abrir várias explicaçôes dos fenômenos magnéticos de Arago e, também, descobrir um novo estado que pode, provavelmente, ter influência em alguns dos mais importantes efeitos das correntes elétricas (Faraday, 1839-1855, p. 265).

O Diário de Faraday não dá nenhuma indicação do motivo pelo qual ele iniciou os novos experimentos. Do início de 1831 a julho do mesmo ano, Faraday estudou figuras acústicas em sólidos e líquidos. Em maio ele retornou rapidamente ao estudo do efeito termoelétrico, e nos dia 18 e 19 de agosto de 1831 ele estava se dedicando a experimentos sobre elaboração de chapas de cobre para impressão de figuras (Faraday in Martin, 1932-1936, p. 360ss).

Sem nenhuma explicação prévia, nas anotações relativas ao dia 29 de agosto de 1831, Faraday começou por descrever um anel de ferro doce (Figura 4) que construiu para o experimento e foi preservado até hoje.

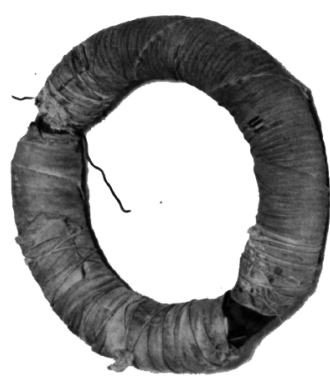

Figura 4: Foto do anel de ferro, utilizado nas experiências de 1831.

Foi feito um anel de ferro [ferro doce] circular, com 7/8 de polegada de espessura e 6 polegadas de diâmetro externo. Várias espiras de fio de cobre foram enroladas ao redor de uma metade do anel, as espiras sendo separadas por barbante e algodão - existiam três extensōes de fio, cada um com aproximadamente 24 pés de comprimento e eles poderiam ser ligados como uma só extensão ou usados como pedaços separados, cada um isolado do outro. Chamarei este lado do anel de A. No outro lado, mas separado por um intervalo, foram enrolados fios em dois pedaços juntos, contabilizando aproximadamente 60 pés em comprimento, a direção sendo como das primeiras espiras; este lado chamarei B (Faraday in Martin, 1932-1936, p. 367).

Faraday acreditava que a passagem de corrente elétrica em um dos enrolamentos poderia induzir uma corrente elétrica no outro enrolamento. Os dois enrolamentos do lado B foram unidos para formar um único, e sua extremidade foi conectada a um fio de cobre passando sobre uma agulha magnética a uma distância de 3 pés do anel. Deste modo, a agulha ao mover-se indicaria a passagem de uma corrente pelo lado B do anel. Uma das espiras do lado A foi conectada com uma bateria de 10 pares de placas, de 4 polegadas quadradas e, com a passagem da corrente pelo lado A, vinda da bateria, uma corrente foi detectada no lado B do anel. 
Imediatamente um efeito sensivel apareceu na agulha. Esta oscilou e estabeleceu-se por fim na posição inicial. Quebrando a conexão do lado A com a bateria, novamente houve uma perturbação na agulha (Faraday in Martin, 1932-1936, p. 367).

Faraday havia encontrado um efeito e, para confirmá-lo, juntou as extremidades das espiras do lado A em um enrolamento único e conectou com a bateria. Um efeito ainda mais forte foi observado na agulha. A corrente somente surgia em B imediatamente após conectar o lado A com a bateria ou imediatamente ao desconectá-lo. Quando a corrente estava fluindo continuamente no lado A, nada ocorria no lado B.

Note-se que, neste primeiro experimento bem sucedido, depois de anos de tentativas, o que Faraday encontrou foi o efeito de uma corrente elétrica sobre outra, e não de um ímã sobre uma corrente elétrica. Sob o ponto de vista didático, geralmente se introduz a indução eletromagnética de outra forma.

Na seqüência do mesmo dia (29 de agosto de 1831) Faraday procurou obter efeitos químicos e fagulhas, indicaçôes de que estava tentando verificar se o efeito obtido era realmente elétrico (como a corrente obtida através de uma pilha) ou de algum outro tipo.

No dia seguinte, Faraday fez outras experiências sempre com resultados de mesmo caráter, ou seja, só ocorrendo quando se estabelecia ou se interrompia a conexão com a bateria. Isso levou Faraday à seguinte indagação:

Não poderiam esses efeitos temporários estarem conectados com as causas da diferença entre os efeitos de metais em repouso e em movimento, nos experimentos de Arago? (Faraday in Martin, 1932-1936, p. 369).

Faraday parece ter começado a entender que o disco estacionário, nos experimentos de Arago, não poderia produzir qualquer efeito sobre o ímã, sendo esses efeitos indutivos como no experimento do anel e, portanto, obtidos somente quando o disco estava em movimento relativo ao ímã. Uma evidência disso é que em 23 de setembro de 1831, Faraday escreveu ${ }^{19}$ a seu amigo R. Phillips contando que havia voltado a se ocupar com o eletromagnetismo e que tinha uma idéia, embora ainda não a pudesse confirmar, de que sabia por que metais eram magnéticos quando em movimento, apesar de não o serem (geralmente) quando em repouso. Evidentemente, essa idéia motivou Faraday em suas atividades e certamente direcionou alguns dos experimentos seguintes.

Em um deles utilizou um cilindro de ferro e a hélice L [o pequeno cilindro de ferro de 7/8 de espessura e 4 polegadas de comprimento, envolvido com quatro pedaços de fio de 14 pés de comprimento cada].

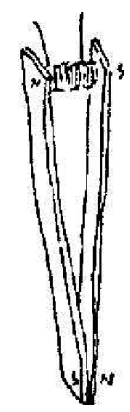

Figura 5: Pinça formada por dois ímãs: obtenção de corrente induzida pela ação de um ímã permanente.

${ }^{19}$ The correspondence of Michael Faraday, carta 515 (James, 1991, vol. 1, p.579). 
Todos os fios foram unidos em uma única hélice e conectados à hélice indicadora, a distância, pelo fio de cobre: depois o ferro foi colocado entre os pólos da barra magnética, como em um dos primeiros experimentos e na figura anterior. Toda vez que o contato magnético no norte ou sul foi estabelecido ou quebrado, existiu movimento magnético na hélice indicadora, o efeito sendo como nos primeiros casos, não permanente, mas meramente empurrando ou puxando. Mas, se o contato elétrico (isto é, através do fio de cobre) era quebrado, então as disjunçôes e contatos não produziram qualquer efeito. Assim, distinta conversão de magnetismo em eletricidade (Faraday in Martin, 1932-1936, p. 372).

Este último experimento foi um grande sucesso, pois Faraday obteve (pela primeira vez) corrente elétrica induzida pela ação de um imã permanente, produzindo através desse dispositivo uma rápida variação magnética no cilindro de ferro. Nenhuma bateria foi utilizada. A "pinça" formada pelos dois ímãs (Figura 5) produzia o efeito desejado. Deve-se notar que esse tipo de experimento é muito mais fácil de reproduzir do que o experimento descrito nos livros didáticos, de aproximar e afastar rapidamente um ímã de uma bobina.

Após esses resultados, Faraday parece ter ficado em dúvida sobre a causa dos fenômenos. Nos experimentos iniciais com o anel, havia uma corrente elétrica que produzia um efeito no segundo enrolamento. No último experimento descrito, o efeito era produzido apenas por uma variação magnética. Seriam dois fenômenos diferentes? Seria possível obter algum efeito sem a presença de um núcleo de ferro?

Ele confirmou essa hipótese com experimentos realizados no dia 29 de setembro de 1831, nos quais, pela primeira vez, utilizou a expressão "efeito induzido" para descrever o fenômeno.

Os resultados que eu havia obtido nessa época com imãs, levaram-me a acreditar que a corrente da bateria através de um fio induzia realmente uma corrente semelhante através do outro fio, mas que ela continuava apenas durante um instante, e tinha a mesma natureza da onda elétrica que passa através do choque de uma garrafa de Leyden, e não como a corrente de uma bateria voltaica, e por isso poderia magnetizar uma agulha de aço, embora afetasse pouco o galvanômetro (Faraday, 1839-1855, p. 266).

Nesse momento, Faraday já estava ciente de que era possível produzir correntes elétricas tanto a partir de uma outra corrente elétrica (a indução volta-elétrica) como pela variação magnética brusca (no experimento com a "pinça" formada por dois ímãs). Embora ele já tivesse tentado obter efeitos pela aproximação e afastamento de ímãs, não tinha obtido resultados, mas tais efeitos deviam existir. Por isso ele insistiu e no dia 17 de outubro de 1831 Faraday realizou o seu experimento mais conhecido, a indução de corrente pela movimentação de uma barra magnética dentro de uma bobina.

A descrição dada no diário se refere a um cilindro de papel, oco, coberto por 8 enrolamentos [todos com mesma direção] de fio de cobre, com aproximadamente 220 pés de comprimento, separados por algodão - identificado como "arranjo O".

As oito extremidades das hélices, em uma extremidade do cilindro, foram limpas e rapidamente unidas como um feixe. $\mathrm{O}$ mesmo foi feito na outra extremidade. Essas extremidades compostas foram conectadas a um galvanômetro por longos fios de cobre, como vemos na Figura 6.

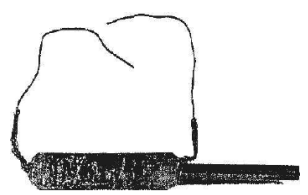

Figura 6: Foto do cilindro de papel e do ímã em barra, utilizados no famoso experimento de 17 de outubro de 1831. 
Depois, um imã cilíndrico de 3/4 de polegadas de diâmetro e 8 1/2 polegadas de comprimento, teve uma extremidade inserida dentro da hélice - depois foi rapidamente empurrada em todo seu comprimento, e a agulha do galvanômetro moveu-se - depois, foi empurrada para fora e novamente a agulha se moveu, mas em direção oposta. Este efeito se repetiu todas as vezes que o imã era colocado dentro ou retirado e portanto, uma onda de eletricidade foi assim produzida pela mera aproximação de um imã e não por sua formação in situ (Faraday in Martin, 1932-1936, p. 375).

Ou seja, o princípio descoberto era que o movimento de um ímã gera uma corrente elétrica no condutor. $\mathrm{O}$ trabalho realizado por Faraday no final de 1831 complementou a descoberta do eletromagnetismo por Ørsted, mostrando a existência de um fenômeno inverso (produção de efeitos elétricos pelo magnetismo) e fornecendo a base necessária para o desenvolvimento de uma nova área de pesquisas.

\section{Considerações finais}

Passaram-se 10 anos desde as primeiras investigaçôes de Faraday sobre eletromagnetismo até a elaboração da lei da indução. Além disso, foram 9 anos desde sua entrada na livraria até sua chegada aos laboratórios da Royal Institution, e 8 anos aprendendo a fazer pesquisa experimental sob a tutela de Humphry Davy.

Essa longa história construída por Faraday dificilmente pode ser contada em uma única frase. Este trabalho enfocou apenas alguns fragmentos dessa história, aqueles que nos parecem essenciais para a compreensão da dimensão das primeiras contribuições de Faraday ao desenvolvimento do eletromagnetismo.

A fase de dependência intelectual de seu mentor, as primeiras pesquisas independentes, o estudo teórico e experimental do trabalho de outros cientistas, os pressupostos teóricos, o diálogo e a troca com outros cientistas, etapas que antecederam a produção autônoma que resultou na Lei da Indução, mostram que tempo e dedicação foram elementos fundamentais no trabalho desse cientista.

O trabalho de Faraday mostra-se assim um bom exemplo de que a evolução científica se faz com muita pesquisa, com resultados positivos e negativos, com debates dentro da comunidade, com conflitos e, principalmente, com investigaçōes em torno de hipóteses e idéias. Elementos importantes para uma discussão sobre a Ciência que devem ser levados para as salas de aula, juntamente com a valorização do trabalho experimental ${ }^{20}$.

Salientamos ainda que, se a evolução da Ciência não se conquista de maneira simples e linear, tampouco é fácil conhecer a História da Ciência. O longo tempo e a diversidade de tarefas despendidas nessa pesquisa mostram que é ilusório acreditar que os professores, de forma geral, estão capacitados para levar a História da Ciência à sala de aula.

Acreditamos que esse objetivo só poderá ser alcançado com parcerias entre investigadores e professores de Ciências, através do esforço daqueles professores que tiverem interesse e disponibilidade para enfrentarem a busca independente por tais conhecimentos, e pela luta de melhoria na formação específica. Em resumo, se a prática de ensino e pesquisa em História e Filosofia da Ciência fizerem parte do currículo de formação dos professores de Ciências em uma abordagem crítica do fazer científico e de sua história.

\footnotetext{
${ }^{20}$ Diversas temáticas podem ser exploradas a partir do estudo histórico do trabalho de Faraday, por exemplo, a busca de teorias unificadoras dentro da Ciência. Saraiva (2003) sugere algumas possibilidades para sua utilização no ensino de Ciências. 


\section{Referências}

AMPÈRE, J. M. Expériences relatives à de nouveaux phénomènes électro-dynamiques. Annales de Chimie et de Physique, Paris, v. 20, p. 60-74, 1822.

ARAGO, D. F. J. L'action que les corps aimantés et ceux qui ne le sont pas exercent les uns sur les autres. Annales de Chimie et de Physique, Paris, v. 28, p. 325-326, 1825.

BONJORNO, J. R. et al. Física: história \& cotidiano. São Paulo: FTD, 2003. 3 v.

BRASIL. Ministério de Educação. Secretaria de Educação Média e Tecnológica. Parâmetros curriculares nacionais: ensino médio. Brasília: MEC/Semtec, 2002.

FARADAY, M. Experimental researches in electricity. New York: Dover, 1965. 3 v.

. Electro-magnetic current. Quarterly Journal of Science, v. 19, p. 338, 1825.

. Historical statement respecting electro-magnetic rotation. Quarterly Journal of Science, v. 15 , p. $288-92,1823$.

. Note on new electro-magnetical motions. Quarterly Journal of Science, v. 12, p. 416-421, 1822a.

. Historical sketch of electro-magnetism. Annals of Philosophy, v. 9, p. 107-117, 1822b.

. Historical sketch of electro-magnetism. Annals of Philosophy, v. 2, p. 195-290,1821a.

. On some new electro-magnetical motions, and on the theory of magnetism. Quarterly

Journal of Science, v. 12, p. 74-96, 1821 b.

Sur les mouvemens électro-magnétiques et la théorie du magnétisme. Annales de Chimie et de Physique, Paris, v. 18, p. 377-70, 1821c.

. Description of an electro-magnetical apparatus for the exhibition of rotary motion.

Quarterly Journal of Science, v. 12, p. 283-285, 1821d.

GRUPO DE REELABORAÇÃO DO ENSINO DE FÍSICA. Física 3: eletromagnetismo. 3. ed. São Paulo: Editora da Universidade de São Paulo, 1998.

JAMES, F. A. J. L. (Ed.). The correspondence of Michael Faraday. Stevenage: Institution of Electrical Engineers, 1991. v. 1.p. 1811-1831.

MARTIN, T. Faraday's diary: being the various philosophical notes of experimental investigation made by Michael Faraday, D. C. L., F. R. S., 1820-1862. London: G. Bell and Sons, 1932-1936. 7 v.

MARTINS, R. A. Orsted e a descoberta do eletromagnetismo. Cadernos de História e Filosofia da Ciência, Campinas, v. 10, p. 89-114, 1986. 
. Sobre o papel da história da ciência no ensino. Boletim da Sociedade Brasileira de História da Ciência, São Paulo, v. 9, p. 3-5, 1990.

MARTINS, R. A.; SILVA, C. C. Newton and colour: the complex interplay of theory and experiment. Science \& Education, Dordrecht, v. 10, n. 3, p. 287-305, 2001.

MATTHEWS, M. R. Science teaching: the role of history and philosophy of science. New York: Routledge, 1994.

MÁXIMO, A.; ALVARENGA, B. Curso de física. São Paulo: Scipione, 2000. 3 v.

ORSTED, H. C. Experiências sobre o efeito do conflito elétrico sobre a agulha magnética. Cadernos de História e Filosofia da Ciência, Campinas, v. 10, p. 115-122, 1986.

PARANÁ, D. N. S. Física para o ensino médio. 2. ed. São Paulo: Ática, 1999.

PEDUZZI, L. O. Q. Sobre a utilização didática da história da ciência. In: PIETROCOLA, M. (Org.). Ensino de física: conteúdo, metodologia e epistemologia numa concepção integradora. Florianópolis: Editora da UFSC, 2001.

SARAIVA, C. A. A. Evolução histórica da abordagem do eletromagnetismo e indução eletromagnética nos livros de texto para o ensino secundário. 2003. Dissertação (Mestrado)-Universidade de Aveiro, Aveiro, 2003.

SILVA, J. A.; PINTO, A. C.; LEITE, C. Projeto escola e cidadania: física (as leis do eletromagnetismo). São Paulo: Editora do Brasil, 2000.

TYNDALL, J. Faraday as a discoverer. New York: Thomas Y. Crowell, 1961.

WILLIAMS, L. P. Michael Faraday: a biography. New York: Simon and Schuster, 1971. 